MEDICAL PRACTICE

\title{
Can Colonic Bacterial Metabolites Predispose to Cholesterol Gall Stones?
}

\author{
THOMAS S. LOW-BEER, ERU W. POMARE
}

British Medical fournal, 1975, 1, 438-440

\section{Summary}

The cholesterol content of biliary lipids increased significantly when 16 healthy volunteers ingested deoxycholic acid (DC) for two weeks in a daily dose of 100-150 mg. Serum cholesterol also fell significantly to $88 \%$ of the baseline levels. Since DC is formed in the colon we suggest that populations in whom there is a high colonic absorption of bacterially metabolized cholate-that is, DC-have an increased predisposition to cholesterol gall stones.

\section{Introduction}

In the U.K. gall stones usually contain over $50 \%$ cholesterol. ${ }^{1}$ Cholesterol is normally kept in solution in bile by the detergent action of bile salts and lecithin, and cholesterol gall stones can be formed only when there is a relative excess of cholesterol over detergent. ${ }^{2}$

Once formed, cholesterol gall stones can be dissolved by the administration of chenodeoxycholate $(\mathrm{CDC}){ }^{3}$ a bile salt normally present and synthesized in the liver from cholesterol. The action of CDC is now thought to be due mainly to its effect on cholesterol metabolism, ${ }^{45}$ so that CDC administration reduces the secretion of cholesterol but not that of bile salts. ${ }^{6}$ In this respect CDC conjugates differ from those of cholate and its bacterial metabolite deoxycholate (DC), the other two main bile salts in bile. These do not appear to reduce cholesterol secretion when fed to laboratory animals, ${ }^{45}$ and cholic acid

\footnotetext{
University Department of Medicine, Bristol Royal Infirmary, Bristol BS2 8HW

THOMAS S. LOW-BEER, B.M., M.R.C.P., Lecturer in Medicine ERU W. POMARE, M.B., M.R.A.C.P., Research Fellow
}

administration has been ineffective in dissolving human gall stones. ${ }^{3}$

We have previously shown that an increase in the recirculation of DC reduces the amount of CDC in bile by selectively suppressing its synthesis. ${ }^{7} 8 \mathrm{DC}$ might therefore be an important determinant of cholesterol saturation in bile since it suppresses the one bile salt known to decrease the secretion of cholesterol. The present study investigates the effect of increasing biliary DC on the saturation of cholesterol in bile.

\section{Methods}

Sixteen healthy medical students and hospital staff volunteered for these studies. Nine were men and seven were women. Their ages ranged from 21 to 54 years. The effect of $\mathrm{DC}$ administration on the composition of the bile salt pool in seven of them has already been reported. ${ }^{7} 8$

Fasting duodenal bile samples $(3-5 \mathrm{ml})$ were obtained by intubation after an intravenous injection of pancreozymin (Boots). Each subject then took $100-150 \mathrm{mg}$ DC (Weddel Pharmaceuticals) daily in divided doses for an average of two weeks. A further 3-5 $\mathrm{ml}$ of fasting duodenal bile was then obtained, and in nine subjects a third sample was aspirated two to three weeks after discontinuing DC.

Aliquots of fresh duodenal bile were assayed for total bile salts ${ }^{\circ}$ and total phospholipid. ${ }^{10}$ Biliary cholesterol was assayed ${ }^{11}$ after Folch extraction. ${ }^{12}$ The results were expressed as a molar percentage of total biliary lipids - that is, moles cholesterol $\div$ moles (cholesterol + bile salts + phospholipid) $\times 100$

Fasting blood samples were obtained in 13 of the subjects at the same time as duodenal intubation was performed for estimation of serum cholesterol and triglyceride, bilirubin, alkaline phosphatase, and aspartate aminotransferase levels.

\section{Results}

The effect of feeding DC on the percentage of cholesterol in the bile is shown in the fig. A rise in cholesterol occurred in 10 of the 16 subjects and was significant in the group as a whole 


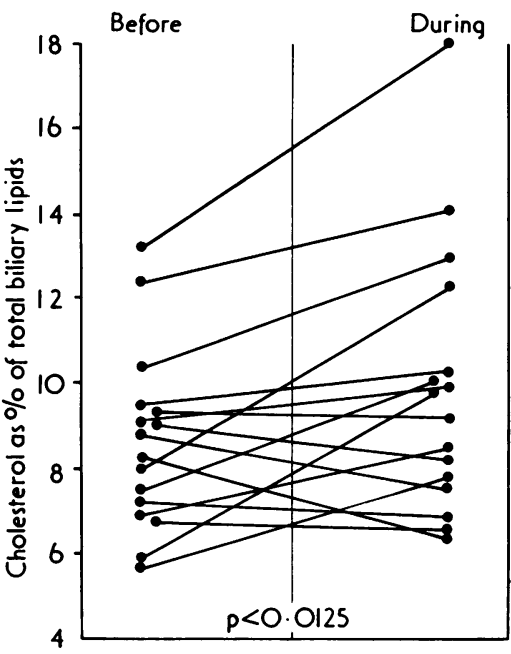

Effect of deoxycholic acid administration on cholesterol content of biliary lipids measured in bile aspirated from duodenum after overnight fast.

(paired Student's $t$ test: $t=2.57 ; \mathrm{P}<0.0125$ ), rising from a mean of $8.6 \pm 0.5 \%$ (S.E.) to $9.9 \pm 0.7 \%$. No differences could be detected between the six subjects in whom the biliary cholesterol did not rise and the rest with regard to age, sex, bile salt composition, or serum lipid levels. The results remained significant $(P<0.005)$ when the bile lipid composition was expressed as a "lithogenic index" (calculated from Thomas and Hofmann's ${ }^{13}$ equation based on the pooled data of Hegardt and Dam $^{14}$ and Holzbach et al. ${ }^{15}$ In the nine subjects whose bile composition was measured two to three weeks after discontinuing DC both the rise in biliary cholesterol associated with taking DC and the fall after discontinuing it were statistically significant $(\mathbf{P}<0.05$ and $\mathbf{P}<0.025$ respectively). In each of the six in whom it rose with therapy it subsequently fell. The mean values before starting and after stopping DC feeding differed by only $0.08 \%$.

The effect of DC on the proportion of bile salts and phospholipid in bile showed no statistically significant trend (table I).

Serum cholesterol levels, measured in 13 subjects, fell significantly while taking DC to an average of $88 \%$ of the original value (table II). In the nine subjects whose levels were measured again after stopping DC both the fall and the subsequent rise in serum cholesterol levels were significant $(t=$ $2.28, \mathrm{P}<0.05$; and $t=4.60, \mathrm{P}<0.01$ respectively). The amount of change in serum cholesterol did not correlate significantly with that in biliary cholesterol. No consistent or significant change in serum triglyceride levels were noted.

TABLE I-Biliary Lipids (Mean \pm S.E. of Mean) Measured in 16 Subjects before and after Two Weeks' Treatment with Deoxycholic Acid. Results Expressed as Molar Percentage of Total Biliary Lipids (see Text)

\begin{tabular}{|c|c|c|c|}
\hline & Cholesterol & Bile Salt & Phospholipid \\
\hline $\begin{array}{l}\text { Before treatment } \\
\text { During treatment }\end{array}$ & $\begin{array}{l}8.6 \pm 0.5 \\
9.9 \pm 0.8\end{array}$ & $\begin{array}{l}68.1 \pm 0.9 \\
67.8 \pm 1.5\end{array}$ & $\begin{array}{l}23 \cdot 2 \pm 0.7 \\
22.3 \pm 1 \cdot 1\end{array}$ \\
\hline Paired $t$ test $\left\{\begin{array}{l}t= \\
\mathbf{P}\end{array}\right.$ & $\begin{array}{l}+2.57 \\
<0.0125\end{array}$ & $\begin{array}{l}-0.35 \\
\text { N.S. }\end{array}$ & $\begin{array}{l}-1 \cdot 15 \\
\text { N.S. }\end{array}$ \\
\hline
\end{tabular}

N.S. $=$ Not significant

TABLE II-Mean ( \pm S.E. of Mean) Fasting Serum Lipid Levels Measured in 13 Subjects before and after Two Weeks' Treatment with Deoxycholic Acid

\begin{tabular}{l|c|c}
\hline & $\begin{array}{c}\text { Cholesterol } \\
(\mathrm{mmol} / \mathrm{l})\end{array}$ & $\begin{array}{c}\text { Triglyceride } \\
\text { (mmol } / 1)\end{array}$ \\
\hline $\begin{array}{l}\text { Before treatment } \\
\text { During treatment }\end{array}$ & $\begin{array}{c}4.80 \pm 0.30 \\
4.22 \pm 0.26\end{array}$ & $\begin{array}{c}0.70 \pm 0.07 \\
0.76 \pm 0.09\end{array}$ \\
\hline Paired $t$ test $\left\{\begin{array}{l}t= \\
\mathrm{P}\end{array}\right.$ & $\begin{array}{c}-2.32 \\
<0.025\end{array}$ & $\begin{array}{l}0.68 \\
\text { N.S. }\end{array}$ \\
\hline
\end{tabular}

Each subject was questioned about alterations in bowel habit and other symptoms. None were noted. There was no indication from liver function tests of hepatotoxicity.

\section{Discussion}

Our results show that the ingestion of DC in a daily dose of $100-150 \mathrm{mg}$ causes a significant but reversible increase in the cholesterol content of biliary lipids. This dose constitutes at most $1 \%$ of the bile salt perfusing the small bowel daily. It is probably equal to the amount of newly dehydroxylated cholate which is normally absorbed into the enterohepatic circulation from the colon as DC. We have already shown that DC given to seven of these subjects consistently produced an enlarged DC pool and a correspondingly reduced CDC pool without significantly altering the size of the bile salt pool as a whole. ${ }^{78}$ Therefore, the increased cholesterol saturation was not due to a reduced availability of the bile salts but rather to a qualitative change in the bile salts present in the enterohepatic circulation.

The present findings are consistent with current concepts of the regulation of bile salt and cholesterol synthesis. Evidence so far suggests that both cholate and DC suppress the activity of the rate-limiting enzyme controlling cholesterol synthesis in the liver to the same extent as that of the enzyme controlling cholesterol catabolism to bile salts. CDC, however, suppresses the activity of hydroxymethylglutaryl coenzyme A reductase controlling synthesis relatively more than that of cholesterol $7 \alpha$ hydroxylase controlling catabolism. ${ }^{4}$ Possibly this difference in the effects of bile salts on hepatic metabolism may partly explain our results.

Since DC is normally formed in the colon, ${ }^{16}$ our results suggest that excessive absorption of the products of bacterial dehydroxylation of bile salts in the colon may predispose to gall stones. DC is likely to be the most important of these since lithocholic acid, the analogous dehydroxylation product of $\mathrm{CDC}$, is poorly soluble in the colon and therefore little is absorbed and present in the bile. ${ }^{17}$ Several studies have shown a trend towards an increased proportion of DC in the bile of patients with gall stones. ${ }^{18} 19$ These patients also tend to secrete bile more completely saturated with cholesterol. An increased proportion of DC in the bile of patients with gall stones may, however, simply reflect the greater exposure of the bile salt pool to colonic bacteria due to the increased cycling of the pool. ${ }^{20}$ 21 Further studies would be needed to show that this situation preceded the cholelithiasis. Nevertheless, an increased proportion of DC in a small and frequently cycling bile salt pool may help to explain the significantly increased secretion of cholesterol reported in gall-stone patients, in whom bile salt synthesis and secretion rate are not greatly abnormal. ${ }^{21}{ }^{22}$ Other explanations have been proposed for the secretion of bile supersaturated with cholesterol. Overeating, ${ }^{23}$ obesity, ${ }^{24}$ and the administration of certain sex hormone ${ }^{25}$ have been implicated, as has an interruption of the enterohepatic circulation during the overnight fast. ${ }^{26} 27$

Epidemiological studies support a relationship between biliary $\mathrm{DC}$ and the prevalence of gall stones. Bile from Mozambique ${ }^{28}$ and faeces from East Africa ${ }^{29}$ contain less DC than do British bile and faeces. The prevalence of gall stones in Britain is high compared with sub-Saharan Africa. ${ }^{30}$ This difference may be related to the different intake of dietary fibre, which is known to affect colonic function. ${ }^{31}$ The diet of the British is said to be lower in fibre than in most of Africa, ${ }^{31}$ and when it is supplemented with fibre in the form of wheat bran there is a decrease in the proportion of DC in bile and a reciprocal increase in CDC. ${ }^{32}$

Since DC is synthesized from cholate mainly in the colon ${ }^{16}$ we suggest that the absorption of the products of colonic bacterial activity may increase the saturation of bile with cholesterol. This effect may be important in the predisposition to cholesterol gall stone formation.

An interesting and unexpected finding was the effect of DC 
administration in lowering the serum cholesterol level. This has been reported previously. ${ }^{33}$ The effect of bile acids on cholesterol metabolism has been known for a long time and has recently been reviewed. ${ }^{34}$ No simple interpretation of previous work, however, satisfactorily explains the hypocholesterolaemic effect of DC. Further work is in progress to study the influence of bile salt metabolism on plasma lipid composition.

We thank Miss Cerys White for invaluable technical help, Dr. K. W. Heaton for his critical evaluation of the text, and Professor Alan Read for his encouragement. Weddel Pharmaceuticals and Kellogg (G.B.) kindly provided grants to support this research.

Correspondence should be addressed to Dr. T. S. Low-Beer.

\section{References}

${ }^{1}$ Sutor, D. J., and Wooley, S. E., Gut, 1971, 12, 55.

2 Redinger, R. N., and Small, D. M., Archives of Internal Medicine, 1972 130, 618.

Thistle, J. L., and Hofmann, A. F., New England fournal of Medicine, $1973,289,655$.

4 Schoenfield, L. J., Bonorris, G. G., and Ganz, P., fournal of Laboratory and Clinical Medicine, 1973, 82, 858.

${ }^{5}$ Shefer, S., et al., fournal of Lipid Research, 1973, 14, 573.

- Northfield, T. C., et al., Gastroenterology, 1973, 64,780.

7 Low-Beer, T. S., Pomare, E. W., and Morris, J. S., Nature New Biology, 1972, 238, 215 .
8 Pomare, E. W., and Low-Beer, T. S., Clinical Science and Molecular Medicine. In press.

- Iwata, T., and Yamasaki, K., Fournal of Biochemistry, 1964, 56, 424.

10 King, E. J., Biochemical fournal, 1932, 26, 292.

11 Watson, D., Clinica Chimica Acta, 1960, 5, 637. Foich, J., Lees, M., and Sloane Stanley, G. H., Fournal of Biological Chemistry, 1957, 226, 497.

13 Thomas, P. J., and Hofmann, A. F., Gastroenterology, 1973, 65, 698.

Hegardt, F. G., and Dam, H., Zeitschrift für Ernährungswissenschaft, 1971, $10,223$.

${ }^{15}$ Holzbach, R. T., et al., fournal of Clinical Investigation, 1973, 52, 1467.

16 Morris, J. S., Low-Beer, T. S., and Heaton, K. W., Scandinavian fournal of Gastroenterology, 1973, 8, 425.

17 Palmer, R. H., Archives of Internal Medicine, 1972, 130, 606.

18 Fisher, M. M., and Yousef, I. M., Canadian Medical Association Fournal, $1973,109,190$.

19 Pomare, E. W., and Heaton, K. W., Gut, 1973, 14, 885.

20 Low-Beer, T. S., and Pomare, E. W., British Medical fournal, 1973, 2, 338

21 Northfield, T. C., and Hofmann, A. F., Lancet, 1973, 1, 747.

22 Grundy, S. M., et al., Metabolism, 1974, 23, 67.

${ }^{23}$ Sarles, H., et al., Scandinavian fournal of Gastroenterology, 1971, 6, 189 Grundy, S. M., Metzger, A. L., and Adler, R. D., fournal of Clinical Investigation, $1972,51,3026$.

25 Boston Collaborative Drug Surveillance Program, New England fournal of Medicine, 1974, 290, 15.

26 Shaffer, E. A., Braasch, J. W., and Small, D. M., New England fournal of Medicine, 1972, 287, 1317

${ }^{27}$ Metzger, A. L., et al., New England fournal of Medicine, 1973, 288, 333. ${ }^{28}$ Mirvisch, S. S., British fournal of Cancer, 1964, 18, 478.

29 Hill, M. J., et al., Lancet, 1971, 1, 95.

30 Heaton, K. W., Clinics in Gastroenterology, 1973, 120, 67.

31 Cummings, J. H., Gut, 1973, 14, 69.

32 Pomare, E. W., and Heaton, K. W., British Medical Fournal, 1973, 4, 262.

33 Yamasaki, K., et al., fournal of Biochemistry, 1959, 46, 807.

34 Wilson, J. D., Archives of Internal Medicine, 1972, 130, 493.

\title{
Occasional Survey
}

\section{Diseases Causing End-stage Renal Failure in New South Wales}

\author{
J. H. STEWART, S. W. MCCARTHY, \\ EILEEN GALLERY, J. F. MAHONY \\ B. G. STOREY, B. A. ROBERTS,
}

British Medical fournal, 1975, 1, 440-443

15-55 in New South Wales was estimated to be at least 34 new cases per million of total population each year.

\section{Summary}

The nature of the original renal disease was determined in $\mathbf{4 0 3}$ consecutive cases of end-stage renal failure, in $\mathbf{3 1 7}$ of which the clinical diagnosis was corroborated by histological examination of the kidney. Five diseases accounted for 20 or more cases-glomerulonephritis (31\% of the total), analgesic nephropathy (29\%), primary vesicoureteral reflux $(8 \%)$, essential hypertension $(6 \%)$, and polycystic kidneys (5\%). In only four cases did renal failure result from chronic pyelonephritis without a demonstrable primary cause. Greater use of micturating cystography and cystoscopy and routine urine testing for salicylate are advocated for earlier diagnosis of the major causes of "pyelonephritis".

The incidence of end-stage renal failure in people aged

\footnotetext{
Kanematsu Memorial Institute, Sydney Hospital, Sydney 2000, Australia

J. H. STEWART, M.R.C.P., Renal Physician

S. W. MCCARTHY, F.A.C.P., Deputy Director of Department of Morbid Anatomy

EILEEN GALLERY, M.R.A.C.P., Registrar, Immunology and Renal Unit J. F. MAHONY, F.R.A.C.P., Physician, Immunology and Renal Unit

Sydney Hospital, Sydney 2000, Australia

B. G. STOREY, F.R.C.S., F.R.A.C.S., Urologist and Transplant Surgeon

B. A. ROBERTS, M.R.A.C.P., M.R.A.C.R., Assistant Director of Department of Diagnostic Radiology
}

\section{Introduction}

Renal replacement therapy is onerous for the patient and costly to the community; morbidity and mortality constantly threaten the dialysis patient and allograft recipient alike. Prevention of renal failure, so desirable in the circumstances, depends primarily on recognition of the diseases which initiate injury to the renal parenchyma. Of the numerically important causes of destructive renal disease "pyelonephritis" offers, in theory at least, the best prospects for prevention or early cure so long as the primary aetiological agent or abnormality is identified.

In this study the primary renal disease has been sought in all people aged 15-55 years, who entered the renal replacement programme or who died with advanced intrinsic renal failure at Sydney Hospital in a seven-year period. An aetiological rather than a pathological diagnosis was made whenever possible in those in whom the renal disorder was identified as pyelonephritis, papillary necrosis, interstitial nephritis, or toxic nephropathy.

\section{Patients}

The records, histological sections of the kidneys, and pyelographic films of all patients who had either presented for dialysis or transplantation or died with intrinsic renal failure (serum 